\title{
Evidências da metropolização do espaço no século XXI: elementos para identificação e delimitação do fenômeno
}

\author{
Evidences of space metropolization in the 21st century: \\ elements to identify and delimit the phenomenon
}

Ednelson Mariano Dota [I]

Francismar Cunha Ferreira [II]

\begin{abstract}
Resumo
Identificar e delimitar o processo de metropolização do espaço têm se constituído como um grande desafio aos estudiosos do urbano, principalmente pelos elementos subjacentes que o constituem. Este artigo apresenta uma proposta teórico-metodológica para identificar e delimitar a metropolização a partir da análise da localização espacial das plantas industriais e logísticas, das condições gerais de produção, da mobilidade pendular para trabalho e da migração. Utilizando-se do processo urbano do Espírito Santo como estudo de caso, foi possível verificar a expansão da metropolização para os municípios não metropolitanos de Aracruz, Linhares e São Mateus, de modo que os elementos utilizados para a análise se mostraram pertinentes para a identificação e a delimitação da metropolização do espaço.
\end{abstract}

Palavras-chave: metropolização; indústria, condições gerais de produção; migração; mobilidade pendular.

\begin{abstract}
The identification and delimitation of the process of metropolization of space has been a challenge for urban researchers, mainly because of its underlying elements. This paper presents a theoretical and methodological proposal for identifying and delimiting metropolization based on the analysis of the spatial location of industrial and logistic plants, the general conditions of production, work commuting, and migration. Using the urban process of the State of Espirito Santo as a case study, we verify the expansion of metropolization to the non-metropolitan municipalities of Aracruz, Linhares and São Mateus, showing that the elements used for the analysis were relevant to the identification and delimitation of the process of space metropolization.
\end{abstract}

Keywords: metropolization; industry; general conditions of production; migration; commuting. 


\section{Introdução}

Os estudos urbanos, econômicos e regionais estão apontando para uma série de novos aspectos que se apresentam no espaço em função da reestruturação do capital. Novas formas de organização produtiva, redefinições na divisão territorial do trabalho e nos fluxos migratórios e pendulares implicam novas formas de produção e organização do espaço, especialmente o espaço urbano.

Diante do cenário em transformação, recorre-se ao conceito de metropolização do espaço, que carrega consigo a ideia da expansão espacial do fenômeno urbano ao mesmo tempo que delimita o tipo de urbanização, intensiva e concentradora de técnicas e recursos. Em linhas gerais, a metropolização constitui-se num processo socioespacial que metamorfoseia o território e imprime características metropolitanas ao espaço, transformando as estruturas preexistentes e engendrando novas morfologias urbanas (Acher, 1998; Lencioni, 2003). Implica a conformação de um urbano que ultrapassa os limites da metrópole, constituindo espaços urbanos materialmente descontínuos, mas integrados por fluxos intensos de pessoas, mercadorias, capitais, informações e outros (Lencioni, 2003).

Um dos grandes desafios impostos aos pesquisadores do fenômeno urbano é o de capturar a materialização e a dimensão desse processo no espaço, visto que muitos dos elementos são subjacentes àquilo que efetivamente se apresenta. Nesse contexto, este artigo tem como objetivo identificar o processo de metropolização utilizando-se (1) da organização espacial produtiva; (2) da distribuição das condições gerais de produção; (3) da mobilidade pendular para trabalho; e (4) da migração, analisando a pertinência dessas variáveis para essa delimitação. Para tal, utiliza como recorte espacial a Região Metropolitana da Grande Vitória (RMGV), apresentando, assim, a aplicação das proposições a um contexto real e atual. Parte-se da hipótese de que o fato das transformações atuais na organização espacial produtiva, da densidade de condições gerais de produção, dos fluxos migratórios e da mobilidade pendular para trabalho não se desenvolverem de maneira homogênea no espaço resulta da própria lógica atual do capital, voltada à produção do espaço por meio do processo de metropolização, não definido e delimitado por lei ou por planejamento estatal. No caso do Espírito Santo, outros artigos (Zanotelli et al. 2014, por exemplo) já apontaram a formação de uma região metropolitana estendida, mas poucos foram os elementos concretos e metodológicos apresentados para confirmar tal hipótese.

Metodologicamente, este trabalho organiza-se a partir de revisão bibliográfica sobre produção e organização do espaço urbano, processo de metropolização do espaço e migração e suas dinâmicas. Foi realizada uma pesquisa junto ao Programa de Comunicação Social regional da bacia (Petrobras, 2019), à Federação das Indústrias do Espírito Santo (Findes, 2018) e a notícias de jornais, para um levantamento sobre as principais plantas industriais e logísticas existentes e projetadas no Espírito Santo. Além disso, buscou-se, junto aos Censos Demográficos de 2000 e 2010, do Instituto Brasileiro de Geografia e Estatística (IBGE), os dados sobre dinâmica migratória (data-fixa), sobre mobilidade pendular para trabalho e sobre os setores de atividades que as pessoas estavam ocupando no Espírito Santo. Foi realizado, ainda, a partir de bases do 
Instituto Jones dos Santos Neves (IJSN, 2015, de Energias de Portugal (EDP, 2017, do Sindicado dos bancários do Espírito Santo, de 2017 e da Telebrás, de 2017, o levantamento do conjunto de elementos constituintes das condições gerais de produção (rodovias, ferrovia, portos, antenas de sinal telefônico, agências bancárias, gasodutos, aeroportos, etc.). Esses dados foram utilizados para a construção de um indicador de densidade dessas condições por município, que permite analisar espacialmente o contorno, os limites e a dinâmica recente da metropolização no Espírito Santo.

\section{Processo urbano contemporâneo}

Soja (2002), Lencioni (2003), Moura (2009), dentre outros, apontam que estamos inseridos em um novo contexto compreendido como sendo da reestruturação produtiva do capital. Esse processo se caracteriza por novas formas de produção e de organização do espaço associado à lógica do capital financeiro. A produção, aqui no sentido largo, reorganiza-se para superar o modelo fordista pela organização flexível. Tal movimento, por um lado, impõe uma série de transformações sociais a partir da reorganização da divisão social e territorial do trabalho e, por outro, tende a metamorfosear o conteúdo espacial, a partir da reorganização da própria forma de produção do espaço, em que o urbano ganha novas morfologias, dimensões e escalas (Acher, 1998).

As possibilidades de análise desse novo contexto são múltiplas, entretanto, procuramos compreendê-lo a partir da concepção de metropolização do espaço, que corresponde ao ápice do processo urbano e se constitui numa determinação histórica da sociedade contemporânea associada à reestruturação do capital (Lencioni, 2003).

Em linhas gerais, a metropolização constitui-se num processo socioespacial que metamorfoseia o território. Ela imprime características metropolitanas ao espaço, transformando as estruturas preexistentes, independentemente de serem esses espaços metropolitanos ou não, ${ }^{1}$ engendrando novas morfologias urbanas com características especificas (Lencioni, 2003; Acher, 1998). Implica a conformação de um urbano que ultrapassa os limites da metrópole, constituindo espaços materialmente descontínuos, mas integrados por fluxos intensos de pessoas, mercadorias, capitais e informações (Leroy, 2000; Acher, 1998; Lencioni, 2003).

A metropolização tem sido objeto de estudo de diversos pesquisadores e campos, geralmente preocupados em compreender as relações entre a globalização, a reestruturação produtiva e o processo urbano. Na tentativa de interpretar essas relações/processos, conceitos têm sido propostos, relacionados à morfologia urbana contemporânea, dentre os quais metápole (Acher, 1998), pós-metrópole e exópolis (Soja, 2002), cidade-região global (Scott et al., 2001), megalópole (Gottman, 1970), cidade informacional (Castells, 1999), urbanização e cidades dispersas (Monclús, 1998), megarregião (Lencioni, 2015) e arranjos urbanos regionais (Moura, 2009).

Apesar de muitos estudos e relevantes avanços, uma dimensão pouco debatida consiste na captura da materialização, da delimitação e da dimensão desse processo no espaço. Algumas propostas para tal foram desenvolvidas, como a de Lencioni (2003), que, 
analisando a realidade do processo urbano de São Paulo, propõe sua captura a partir da análise de dois aspectos importantes que se relacionam dialeticamente: o da desintegração vertical da indústria e o das condições gerais de produção. 0 primeiro aponta para o fato de que fases de um determinado processo produtivo não necessitam obrigatoriamente estarem integradas em uma única unidade produtiva. A indústria passa a atuar por meio de diversas unidades e vai ter, na gestão do capital, o elemento que garantirá o caráter integrador da dispersão territorial das unidades. Além disso, destaca-se que o movimento de desintegração vertical também pode se dar no momento em que a indústria terceiriza parte de seu processo produtivo, não deixando de controlar os ciclos de valorização do capital do seu setor.

Quanto às condições gerais de produção, elas são correspondentes a condições que articulam a produção particular às lógicas gerais da acumulação. Elas dizem respeito às condições que possibilitam não apenas um capital em si, mas um conjunto de capitais. Essas condições podem ser agrupadas em duas categorias, a direta e a indireta. As condições de conexão direta podem ser exemplificadas por rodovias, ferrovias, dutos, portos, aeroportos, telecomunicação, rede de energia, bancos e outros. As de conexão indireta seriam escolas, hospitais, centro de esportes, de cultura, de lazer, dentre outros (Lencioni, 2007).

A distribuição dessas condições no espaço não é homogênea, tendendo a se concentrar em determinadas porções, especialmente no espaço urbano e seu entorno imediato. As condições gerais de produção, especialmente as de ligação direta com a produção e a circulação do capital, necessitam da urbanização, pois, enquanto aglomeração, possibilita o avanço na diminuição do tempo de produção e de circulação, além da ocorrência de centralização de capitais (Smith, 1988). Nesse sentido, tem-se um movimento duplo no qual, ao mesmo tempo que as condições tendem a se concentrar no entorno urbano (intensificação), elas também possibilitam a expansão desse espaço (extensificação).

A própria lógica de distribuição dessas condições funciona como um elemento que ao mesmo tempo possibilita e limita, em parte, a desintegração vertical da indústria ou simplesmente a dispersão industrial.

Assim, a ideia de desterritorialização da indústria, expressando extrema liberdade de localização do capital industrial deve ser colocada em seus devidos termos. Essa ideia de liberdade em relação ao território é originária da percepção de que a localização industrial não é mais tão dependente das fontes de recursos naturais e de matérias-primas, como no passado. Mas, assim considerada, essa liberdade está sendo vista com os olhos do passado. De fato, a revolução dos transportes permitiu esse desenraizamento da indústria em relação àqueles fatores de produção industrial, mas os olhos do presente devem enxergar a emergência de outras condições gerais de produção que estão, em grande parte, adensadas na metrópole e no seu entorno mais próximo e que territorializam a indústria característica desse novo momento. (Lencioni, 2003a, pp. 4 e 5; grifos nossos)

Outra proposta para a delimitação do processo urbano contemporâneo é apontada por Moura (2009). Ela, baseada na realidade do processo urbano brasileiro no contexto da globalização, considerou aspectos como tamanho da população e da economia (produto interno bruto - PIB), intensidade da 
mobilidade pendular, dentre outros. A partir de uma análise de autocorrelação espacial local, Moura (ibid.) conseguiu delimitar o que ela denominou Arranjos Urbanos e Regionais (AURs) que corresponderiam à materialização do processo de metropolização no Brasil.

Por sua vez, Smith (1988), debatendo o papel da escala urbana no processo de conformação do desenvolvimento desigual e combinado, no contexto da produção do espaço subordinado ao capitalismo, aponta que:

Se a escala urbana enquanto tal é a expressão necessária da centralização do capital produtivo, os limites geográficos à escala urbana (que não se deve confundir com os limites administrativos de uma cidade) são determinados, em primeiro lugar, pelo mercado de trabalho local e pelos limites ao deslocamento diário para o trabalho. (p. 197; grifos nossos)

Em síntese, Lencioni (2003), Moura (2009) e Smith (1988) apresentam proposições para delimitação do processo urbano. Acredita-se que elas, individualmente, não dão conta de maneira satisfatória das muitas realidades urbanas brasileiras, sobretudo da metropolização. Quanto à proposta apresentada por Lencioni (2003), convém ressaltar que se aplica à realidade paulista, na qual se verifica um processo específico da organização produtiva da indústria que não é comparável com a realidade de outras regiões. O Espírito Santo seria um exemplo, já que muitas plantas industriais estão subordinadas à gestão que se encontra no Rio de Janeiro ou em São Paulo, além de não ser comum, em suas indústrias, o processo de desintegração vertical. Além disso, os critérios propostos por Moura (2009) não chegam a capturar o processo urbano de muitos lugares e regiões, como foi o caso da
Região Metropolitana da Grande Vitória, que não se configurou como um AUR. $O$ fato de não se adequar à categorização proposta por Moura (ibid.), entretanto, não significa que o processo urbano do Espírito Santo esteja inerte ou às margens das dinâmicas do capitalismo atual, como mostra Zanotelli et al. (2019). Por fim, a proposta de Smith (1988) não revela processos importantes que acompanham dialeticamente a divisão social do trabalho no espaço urbano, pois identificar apenas a mobilidade pendular fisicamente ${ }^{2}$ limita a complexidade das áreas urbanas modernas e de suas atividades em desenvolvimento.

As limitações apontadas não invalidam nem diminuem a importância das contribuições. Além disso, vale ressaltar que, por não serem antagônicas, abrem-se novas possibilidades de análise, a partir da associação das três perspectivas e o acréscimo de novos elementos. Essa associação, proposta deste artigo, permite considerar a expansão do processo urbano contemporâneo a partir da (1) distribuição das condições gerias de produção, da (2) organização espacial produtiva das atividades industriais proposta por Lencioni (2007), da (3) mobilidade pendular proposta por Smith (1998) e Moura (2009) e, acrescentamos, das (4) dinâmicas migratórias, cuja ocorrência tem forte relação com a expansão metropolitana (Cunha, 1994), e das dinâmicas de produção do espaço (Dota, 2015; Cunha, 2016).

Qual o potencial em inserir as dinâmicas migratórias como elemento de análise para a delimitação do processo de metropolização do espaço? De fato, a relação entre urbanização e migração não é nova no Brasil. As principais aglomerações urbanas brasileiras foram impulsionadas pela migração campo-cidade (Singer, 1976), visto que, em função do processo de 
industrialização, apresentaram-se como centralidades ou espaços de atração que emergiram em função das transformações econômicas do País, recebendo volumosos fluxos migratórios e concentrando população.

0 recebimento desses fluxos, que predominaram até a década de 1970, permitiu a rápida expansão em termos de volume, ao mesmo tempo que esteve intimamente relacionado com as transformações na morfologia interna dessas áreas. Como bem mostrou Cunha $(1994 ;$ 2018) para a Região Metropolitana (RM) de São Paulo, a dinâmica migratória intrametropolitana dos fluxos expandia a aglomeração para a periferia e criava novas relações dessas áreas com o centro. Essa expansão não se deu de forma aleatória, mas sempre fortemente relacionada ao processo de produção do espaço urbano. Tal entendimento foi confirmado por Matos (2005) no debate do papel dos movimentos populacionais nas grandes cidades; por Dota (2015) e Cunha (2016) para a RM de Campinas; além de já ter sido amplamente analisada para as principais regiões metropolitanas do Brasil (ver Cunha, 2018).

A novidade, para além da expansão intrametropolitana, foram os fluxos observados com origem nas RMs, mas cujos destinos estavam além dos seus limites (Cunha et al., 2013; Silva, Cunha e Ortega, 2017; Silva, 2018), indicando a expansão da área metropolitana ou, de caráter qualitativamente novo, a criação de novos contextos urbanos que, para o caso paulista, estão denominando "macrometrópole". Da mesma forma, as mudanças observadas na dinâmica da mobilidade pendular nas últimas décadas, com destaque para o crescimento relativo e absoluto dos fluxos extra-RMs (Lobo e Cunha, 2019; Dota, 2019), reforçam esse entendimento, evidenciando a impossibilidade de uso dos limites políticos para análise dos processos e fenômenos metropolitanos.

Em resumo, a análise aqui elaborada busca concatenar quatro elementos (condições gerais de produção, distribuição espacial da indústria, mobilidade pendular e migração) que, pelas diferentes influências que os conformam, podem contribuir para a identificação da dimensão do processo metropolitano em diferentes espaços e escalas, ou seja, identificar a manifestação do urbano mais intenso a partir dos processos sociais, econômicos e espaciais que são próprios desse espaço.

\section{A expansão e a delimitação do processo urbano contemporâneo no Espírito Santo: uma análise teórico-metodológica}

A urbanização do Espírito Santo e a conformação da Região Metropolitana da Grande Vitória (RMGV), ${ }^{3}$ assim como de outras cidades e regiões metropolitanas, se deram em um ritmo acelerado em função do processo de industrialização, que implicou uma urbanização superior a ele (Oliveira, 1982). A urbanização no Espírito Santo, sobretudo no entorno da capital, teve forte relação com os grandes investimentos, que se iniciaram em 1942, no município de Cariacica, com a instalação da Companhia Ferro Aço de Vitória (Cofavi), indústria siderúrgica, hoje privatizada e controlada pela multinacional mexicana Simec. Em 1941, têm-se as primeiras instalações da mineradora Companhia Vale do Rio Doce (CVRD), nos municípios de Cariacica e Vila Velha. Posteriormente, 
na década de 1970, tem-se a implantação dos chamados grandes projetos industriais no Espírito Santo, destacando-se a implantação do Polo de Tubarão, formado pela CVRD (atual Vale) e pela Companhia Siderúrgica de Tubarão (CST, atual Arcelor Mittal), além de contar com os portos de Tubarão e Praia Mole. No município de Anchieta, ao sul da RMGV, deu-se a implantação da mineradora Samarco e do porto de Ubu; e, no município de Aracruz, ao norte da RMGV, a implantação da Aracruz Celulose, atual Suzano, e do porto de Barra do Riacho (Portocel). Além disso, em âmbito estadual tem-se, em 1974, a implantação do Centro Industrial da Grande Vitória I e II (Civit I e II) no município de Serra.

Essas grandes plantas industriais contribuíram para a transformação do conteúdo socioespacial do Espírito Santo. É a partir delas que o estado deixa de ter uma economia agroexportadora e se torna um estado urbano-industrial. De maneira concreta, os efeitos sobre a urbanização podem ser verificados basicamente de duas formas: uma, pela evolução da população urbana, em especial do que veio a ser posteriormente a RMGV; e a outra pela expansão da mancha urbana da RMGV (Dota e Ferreira, 2019).

Mais recentemente, o processo urbano no estado mostrou-se dinâmico, apresentando novas transformações. Destacaram-se novas formas de produção do espaço urbano por meio de condomínios e loteamentos fechados e a ampliação do número de shoppings centers na região metropolitana. Somente entre 2005 e 2013 foram lançadas 68.681 unidades imobiliárias em condomínios fechados na RMGV. Além disso, tem-se, nesse período, o lançamento de sete grandes loteamentos fechados com um total de
4.309 lotes (Ferreira, 2014). Soma-se, ainda, o lançamento de aproximadamente nove condomínios industriais e logísticos e de mais cinco shoppings na região. Em geral, esses empreendimentos trouxeram dinamicidade e conflitos para a região, uma vez que resultam, de certo modo, de captura e apropriação de rendas fundiárias e imobiliárias e implicaram novos processos de redefinição do uso do solo urbano, reorganização da divisão territorial do trabalho e conformação e intensificação de novas formas de segregação.

Diferentemente de outros lugares, a expansão do processo urbano para além da região metropolitana delimitada oficialmente teve início ainda pelos grandes investimentos nos municípios do entorno metropolitano. Os projetos mais recentes seguem o mesmo processo, com muitos deles concentrando-se fora da RMGV, em especial na faixa litorânea do estado, com destaque para os municípios de Aracruz e Linhares e São Mateus, conforme aponta o Quadro 1.

Considerando a relevância para a dinâmica econômica do estado, essas plantas industriais e logísticas representam uma interiorização das atividades produtivas, já que relativizam a concentração exercida pela RMGV. Essa desconcentração, de acordo com Rua (2015a), apresenta-se como um movimento coerente com a estratégia atual dos investimentos, que buscam locais onde as vantagens competitivas são possíveis: são locais fora da região metropolitana, mas relativamente próximos e ligados a ela, graças às condições gerais de produção. No Quadro 1, nota-se que todos os empreendimentos, concluídos ou projetados, possuem sua administração ligada às dinâmicas metropolitanas de Vitória ou mesmo do Rio de Janeiro e de São Paulo. 
Quadro 1 - Principais plantas industriais e logísticas concluídas e projetadas no Espírito Santo pós-2005

\begin{tabular}{|c|c|c|c|c|}
\hline Grande projeto & Estágio & $\begin{array}{l}\text { Empresas } \\
\text { responsáveis }\end{array}$ & Localização & $\begin{array}{l}\text { Escritório } \\
\text { de gestão }\end{array}$ \\
\hline Porto Central & Projeto & $\begin{array}{l}\text { TPK Logística, } \\
\text { Polimix, Porto de } \\
\text { Roterdã e Van } \\
\text { Oord }\end{array}$ & $\begin{array}{l}\text { Presidente } \\
\text { Kennedy }\end{array}$ & Vitória-ES \\
\hline Itaoca Offshore & Projeto & Itaoca Offshore & Marataízes & Vitória-ES \\
\hline Porto de Gamboa & Projeto & Edison Chouest & Itapemirim & Rio de Janeiro \\
\hline UTG-SUL & Concluído (inaugurado em 2010) & Petrobras & Anchieta & $\begin{array}{l}\text { Vitória-ES } \\
\text { e Rio de Janeiro }\end{array}$ \\
\hline UTG-Cacimbas & Concluído (inaugurado em 2006) & Petrobras & Linhares & $\begin{array}{l}\text { Vitória-ES } \\
\text { e Rio de Janeiro }\end{array}$ \\
\hline Petrocity & Projeto & $\begin{array}{l}\text { Petrocity Portos } \\
\text { S.A }\end{array}$ & São Mateus & $\begin{array}{l}\text { Vitória-ES } \\
\text { e Rio de Janeiro }\end{array}$ \\
\hline $\begin{array}{l}\text { Terminal Norte } \\
\text { Capixaba (TNC) }\end{array}$ & Concluído (inaugurado em 2006) & Petrobras & São Mateus & $\begin{array}{l}\text { Vitória-ES } \\
\text { e Rio de Janeiro }\end{array}$ \\
\hline Estaleiro Jurong & Concluído (inaugurado em 2014) & $\begin{array}{l}\text { SembCorp } \\
\text { Marine (SCM) }\end{array}$ & Aracruz & $\begin{array}{l}\text { Aracruz, } \\
\text { Vitória-ES } \\
\text { e Rio de Janeiro }\end{array}$ \\
\hline $\begin{array}{l}\text { Terminal Barra do } \\
\text { Riacho (TBR) }\end{array}$ & Concluído (inaugurado em 2013) & Petrobras & Aracruz & $\begin{array}{l}\text { Vitória-ES } \\
\text { e Rio de Janeiro }\end{array}$ \\
\hline Porto Imetame & Projeto & Imetame & Aracruz & Aracruz \\
\hline $\begin{array}{l}\text { Terminal Portuário de } \\
\text { Uso Múltiplo }\end{array}$ & Projeto & Nutripetro & Aracruz & $\begin{array}{l}\text { Aracruz e } \\
\text { Vitória-ES }\end{array}$ \\
\hline Fábrica de bio-óleo & Projeto & Suzano & Aracruz & São Paulo \\
\hline Mlog & Projeto & Mlog & Linhares & Rio de Janeiro \\
\hline $\begin{array}{l}\text { Terminal São Mateus } \\
\text { Liquiport }\end{array}$ & Projeto & Odebrecht & São Mateus & Rio de Janeiro \\
\hline $\begin{array}{l}\text { Britania } \\
\text { Eletrodomésticos }\end{array}$ & $\begin{array}{l}\text { Fabricação de outros } \\
\text { equipamentos e aparelhos } \\
\text { elétricos }\end{array}$ & $\begin{array}{l}\text { Britania } \\
\text { Eletrodomésticos } \\
\text { S/A }\end{array}$ & Linhares & Joinville-SC \\
\hline $\begin{array}{l}\text { Indústria } \\
\text { encarroçadora de } \\
\text { ônibus }\end{array}$ & Concluído (inaugurado em 2014) & Marcopolo & São Mateus & Caxias do Sul-RS \\
\hline $\begin{array}{l}\text { Indústria de motores } \\
\text { elétricos }\end{array}$ & Concluído (inaugurado em 2011) & Weg motores & Linhares & $\begin{array}{l}\text { Jaraguá do } \\
\text { Sul-SC }\end{array}$ \\
\hline Indústria de bebidas & $\begin{array}{l}\text { Concluído (Inaugurado em } 2002 \\
\text { e 2012) ampliado em } 2016 \text { com a } \\
\text { saída das atividades da Coca-Cola } \\
\text { de Cariacica }\end{array}$ & $\begin{array}{l}\text { Leão alimentos } \\
\text { (Coca Cola) }\end{array}$ & Linhares & São Paulo \\
\hline $\begin{array}{l}\text { Indústria de reboques } \\
\text { e semirreboques }\end{array}$ & Concluído em 2019 & Randon S/A & Linhares & Caxias do Sul-RS \\
\hline Termelétrica LGSA & Concluído em 2008 & $\begin{array}{l}\text { Linhares Geração } \\
\text { S/A }\end{array}$ & Linhares & Vitória-ES \\
\hline
\end{tabular}

Fonte: Petrobras (2019), Findes (2018) e sites das empresas. 


\section{Delimitação das condições gerais de produção no Espírito Santo}

Na busca por identificar e delimitar a distribuição das condições gerais de produção no Espírito Santo e sua relação com a interiorização produtiva, foi construído um indicador de densidade das condições gerais de produção por município. Nesse sentido, consideraram-se apenas os equipamentos que possuem conexão direta com o processo de produção no nível do município, que são rodovias, ferrovias, gasodutos, minerodutos, portos, aeroportos, linhas de transmissão de energia, antenas de telefonia e agências bancárias. Foram atribuídos valores relativos a presença ou ausência dos equipamentos nos municípios, em alguns casos considerando o tipo e a intensidade, conforme o Quadro 2.
Todos os elementos foram analisados para cada um dos 78 municípios do Espírito Santo e, ao final, pôde-se auferir a densidade de condições gerais de produção individualmente, a partir da soma do valor do indicador de presença dos equipamentos. Os resultados foram sistematizados em classes que vão de densidade muito baixa, com a presença de poucos equipamentos, a densidade muito alta, ou seja, maior concentração dos equipamentos e, em outras palavras, maior presença de condições gerais de produção. No Mapa 1 pode ser visualizada a distribuição espacial das condições gerais de produção no Espírito Santo de acordo com sua densidade por municípios.

Nota-se que os municípios com maior densidade de condições gerais de produção são exatamente aqueles que formam a área conurbada da RMGV (Cariacica, Serra, Vila Velha e Vitória). Além disso, destacam-se os municípios com alta densidade localizados no

Quadro 2 - Quadro-matriz para cálculo dos pesos das condições gerais de produção no Espírito Santo por município (2017)

\begin{tabular}{|c|c|c|c|c|c|c|}
\hline & \multicolumn{6}{|c|}{ Indicador de presença } \\
\hline & 0 & 1 & 2 & 3 & 4 & 5 \\
\hline Rodovias & $\begin{array}{l}\text { apenas } \\
\text { vicinais }\end{array}$ & $\begin{array}{l}\text { rodovias } \\
\text { estaduais }\end{array}$ & $\begin{array}{l}\text { rodovias } \\
\text { federais }\end{array}$ & - & - & - \\
\hline Ferrovia & não possui & possui & - & - & - & - \\
\hline Gasoduto & não possui & possui & - & - & - & - \\
\hline Mineroduto & não possui & possui & - & - & - & - \\
\hline $\begin{array}{l}\text { Linhas de transmissão } \\
\text { de energia }\end{array}$ & não possui & possui & - & - & - & - \\
\hline Porto & não possui & possui & - & - & - & - \\
\hline Aeroporto & não possui & possui & - & - & - & - \\
\hline $\begin{array}{l}\text { Antenas de telefone } \\
\text { (quant.) }\end{array}$ & - & até 25 & de 26 a 50 & de 51 a 100 & mais de 100 & - \\
\hline Bancos (agências) & - & até 5 & de 6 a 15 & de 16 a 30 & de 31 a 50 & de 51 a 100 \\
\hline
\end{tabular}

Fonte: os autores (2019). 
Mapa 1 - Densidade das condições gerais de produção por município no Espírito Santo (2017)

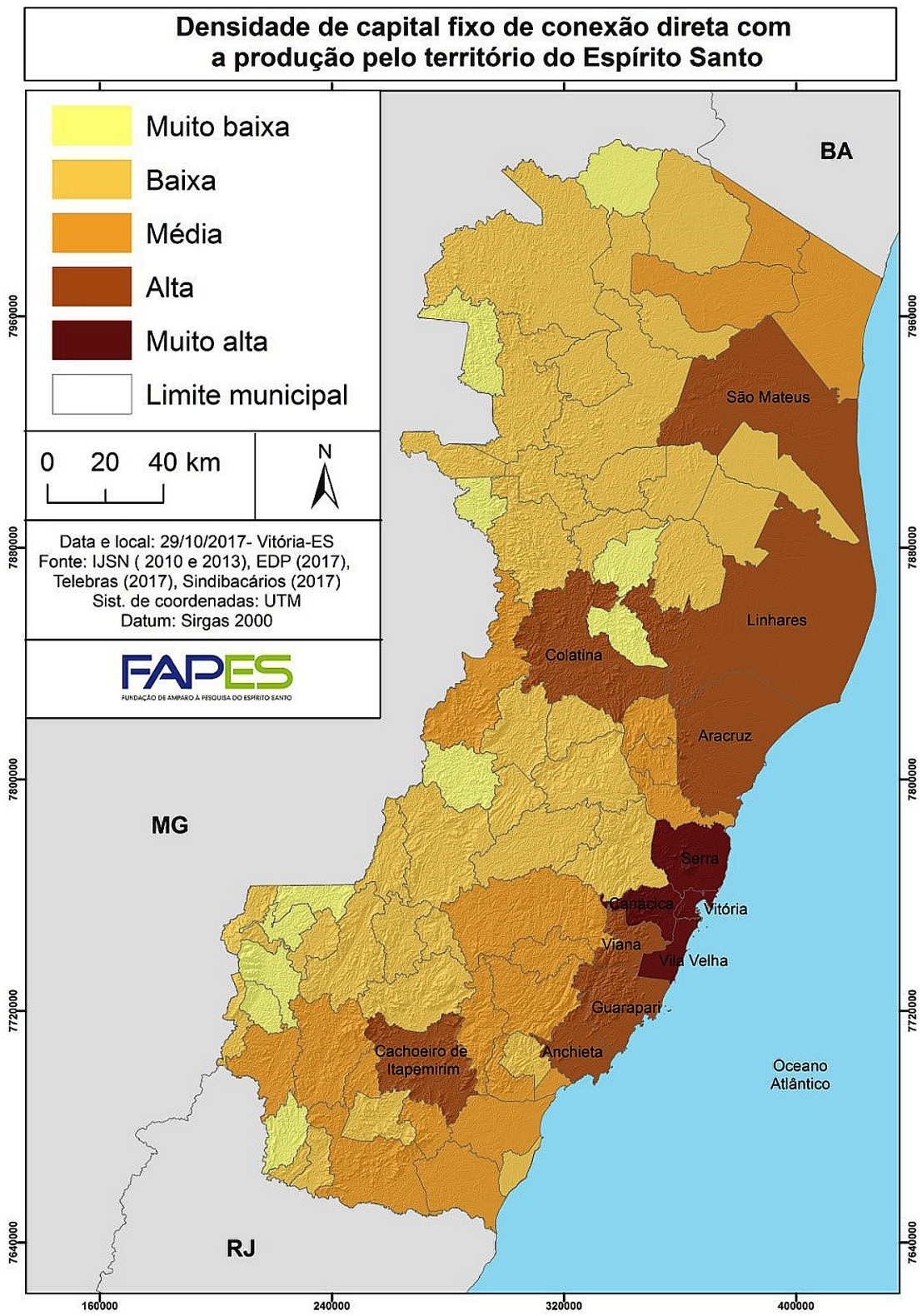

Fonte: IJSN (2010, 2013), EDP (2017), Telebras (2017), Sindibancários (2017). 
litoral sul e norte. Ao sul destaca-se Guarapari, que é integrante da RMGV e Anchieta. No litoral norte destacam-se Aracruz, Linhares e São Mateus. Destacam-se também, no interior do estado, os municípios de Cachoeiro de Itapemirim na porção sul e Colatina no norte. Esses municípios historicamente se destacam por importantes atividades produtivas (Cachoeiro, com a indústria extrativa do mármore e granito, e Colatina, pela indústria têxtil) e por se apresentarem como importantes centros urbanos do interior do estado.

Em linhas gerais, nota-se que as condições gerais de produção se localizam na metrópole e justamente nos municípios que vêm recebendo as plantas industriais e logísticas, especialmente Aracruz, São Mateus e Linhares. Essa distribuição espacial das condições gerais de produção possibilita, assim, que as atividades produtivas e logísticas se desloquem para o interior, sem que se percam relações com a metrópole. Esses movimentos possibilitam uma extensão do processo metropolitano pelo espaço, uma vez que novos fluxos materiais e imateriais que partem na/da/para a metrópole se desenvolvem pelo espaço conformando à centralidade da metrópole no contexto atual da reprodução do capital e à difusão de valores metropolitanos pelo espaço.

A distribuição desigual das condições gerais da produção associada à interiorização das atividades produtivas traz implicações, ainda, sobre outros processos, tais como a divisão territorial do trabalho e os fluxos migratórios.

\section{Divisão territorial do trabalho e os fluxos populacionais}

Quanto à distribuição territorial do trabalho, os dados do IBGE entre 1991 e 2010 indicam que o Espírito Santo apresentou taxa geométrica média anual de crescimento de 4,0\% a.a. de trabalhadores no setor industrial. Esse crescimento, entretanto, foi sentido de maneira diferente nas porções do território capixaba. $\mathrm{Na}$ RMGV, o crescimento foi de $2,7 \%$ e, nos municípios do litoral norte, ainda mais alta, justamente os que receberam e estão recebendo investimentos em plantas industriais e logísticas e que apresentaram alta densidade de condições gerais de produção. Aracruz apresentou uma taxa de $7,23 \%$ de crescimento de trabaIhadores no setor industrial entre 1991 e 2010; Linhares de 6,2\%; e São Mateus apresentou uma taxa de 5,89\%. Os demais municípios do Espírito Santo, em conjunto, apresentam uma taxa de crescimento de 5,0\%. Na Tabela 1 podem ser visualizadas as taxas de crescimento de maneira detalhada.

Faz-se importante destacar que, embora as maiores taxas de crescimento do trabalho no setor industrial estejam fora da RMGV, isso não significa afirmar uma desindustrialização, mas sim o surgimento de novos espaços industriais no estado, em especial nos municípios de Aracruz, Linhares e São Mateus. Nesse sentido, o processo configura-se como uma desconcentração concentrada do trabalho industrial, pois 
Tabela 1 - Pessoas ocupadas em atividades industriais

e taxa de crescimento geométrico médio anual (\% a.a.) no trabalho industrial.

Recortes selecionados, Espírito Santo, 1991-2010

\begin{tabular}{l|r|r|r|r|r|r}
\hline \multirow{1}{*}{$\begin{array}{c}\text { RMGV e } \\
\text { Municípios }\end{array}$} & 1991 & 2000 & 2010 & \multicolumn{3}{c}{ Taxa de crescimento médio geométrico } \\
\cline { 5 - 7 } & & & & $1991-2000$ & $2000-2010$ & $1991-2010$ \\
\hline RMGV & 66.257 & 73.234 & 86.407 & 1,0 & 1,7 & 2,7 \\
Aracruz & 2.866 & 3.460 & 5.791 & 1,9 & 5,3 & 7,3 \\
Linhares & 5.634 & 7.629 & 10.306 & 3,1 & 3,1 & 6,2 \\
São Mateus & 2.602 & 3.460 & 4.607 & 2,9 & 2,9 & 5,9 \\
Outros municípios & 45.322 & 63.650 & 73.618 & 3,5 & 1,5 & 5,0 \\
\hline Total & 122.681 & 151.433 & 180.729 & 2,1 & 1,8 & 4,0 \\
\hline
\end{tabular}

Fonte: Censos Demográficos do IBGE de 1991, 2000 e 2010.

a metrópole não somente continua concentrando o maior número de trabalhadores do setor, como também exerce o controle e a gestão de grande parte das atividades industriais fora dela, além de direcionar a expansão metropolitana para áreas sobre as quais continua a exercer controle.

Por sua vez, a interiorização das atividades produtivas, associada à distribuição desigual das condições gerais de produção, também trouxe transformações sobre os fluxos migratórios no Espírito Santo, cujas análise e descrição permitem comprovar as transformações em andamento. Dota, Coelho e Camargo (2017) apontam que a RMGV e os municípios do litoral norte, especialmente, Aracruz, Linhares e São Mateus, foram os que receberam maior volume de imigrantes na década de 2000; fato novo e que se revela na mesma esteira das transformações na divisão territorial do trabalho no Espírito Santo. Pelo papel de centralidade construído historicamente, o destino principal dos imigrantes em nível estadual continua sendo a RMGV, seguido, agora, dos municípios do litoral norte, em especial Aracruz, Linhares e São Mateus (Tabela 2), tendo ocorrido, na década de 2000, uma modificação substancial da migração nesses municípios (Dota, 2019), justamente como resultado dos investimentos aqui apresentados.

Nos dados da Tabela 2, Aracruz $(2,4 \%$ a.a.), São Mateus (1,9\% a.a.) e Linhares (2,3\% a.a.) foram os municípios que apresentaram taxa de crescimento da população acima da média do estado (1,3\% a.a.) e da RMGV (1,6\% a.a.), com parte importante desse crescimento sendo resultado da migração. Nota-se um importante aumento do volume de imigrantes em Aracruz (71,9\%), Linhares (112,6\%) e São Mateus (41,5\%) no período 2005-2010 em comparação com 1995-2000, bem como aumento do peso da migração na população residente. Os dados da tabela, portanto, indicam que os fluxos migratórios no Espírito Santo seguem, em certa medida, uma desconcentração concentrada, ou seja, a RMGV continua (em valores absolutos) concentrando maior proporção dos imigrantes (54,6\%, no período 
Tabela 2 - Crescimento populacional e imigração na RMGV,

Aracruz, Linhares, São Mateus e outros municípios do Espírito Santo entre 2000 e 2010

\begin{tabular}{|c|c|c|c|c|c|c|c|c|}
\hline \multirow{2}{*}{$\begin{array}{c}\text { RMGV e } \\
\text { Municípios }\end{array}$} & \multicolumn{2}{|c|}{ População residente } & \multirow{2}{*}{$\begin{array}{c}\text { Taxa } \\
\text { geométrica } \\
\text { média de } \\
\text { crescimento } \\
\text { populacional } \\
\text { (\% a.a.) } \\
2000-2010\end{array}$} & \multicolumn{2}{|c|}{ Imigrantes } & \multirow{2}{*}{$\begin{array}{c}\begin{array}{c}\text { Variação } \\
\text { no volume } \\
\text { (\%) }\end{array} \\
1995-2000 \\
2005-2010\end{array}$} & \multicolumn{2}{|c|}{$\begin{array}{l}\text { Proporção de } \\
\text { imigrantes na } \\
\text { população residente }\end{array}$} \\
\hline & 2000 & 2010 & & $1995-2000$ & 2005-2010 & & 2000 & 2010 \\
\hline RMGV & 1.438 .596 & 1.687 .704 & 1,6 & 180.415 & 217.425 & 20,5 & 12,5 & 12,9 \\
\hline Aracruz & 64.637 & 81.832 & 2,4 & 5.993 & 10.301 & 71,9 & 9,3 & 12,6 \\
\hline Linhares & 112.617 & 141.306 & 2,3 & 8.033 & 17.082 & 112,6 & 7,1 & 12,1 \\
\hline São Mateus & 90.460 & 109.028 & 1,9 & 10.793 & 15.272 & 41,5 & 11,9 & 14,0 \\
\hline Outros municípios & 1.391 .187 & 1.495 .082 & 0,7 & 125.420 & 148.951 & 18,8 & 9,0 & 10,0 \\
\hline Total & 3.097 .497 & 3.514 .952 & 1,3 & 330.654 & 409.031 & 23,7 & 10,7 & 11,6 \\
\hline
\end{tabular}

Fonte: Censos Demográficos do IBGE de 2000 e 2010.

1995-2000, e 53,2\%, no período 2005-2010), todavia, destaca-se o aumento dos imigrantes em Aracruz, Linhares e São Mateus, que concentravam $7,5 \%$ do total no primeiro período e aumentaram a participação para $10,4 \%$ no segundo. Mais do que o volume da imigração, o saldo migratório revela as transformações em andamento: no período 1995-2000, Aracruz (-322), Linhares (-4.801) e São Mateus (-3.517) apresentaram saldo migratório negativo de 8,6 mil pessoas, enquanto no período 2005-2010 esse saldo foi positivo em 10,1 mil pessoas.

Com a mudança na espacialidade do fenômeno, há também novas configurações quanto às modalidades observadas. Se antes pessoas migraram quase que exclusivamente para a metrópole, hoje um importante fluxo corresponde à saída de pessoas dela rumo ao interior. Não se trata, entretanto, de todo interior, mas sim dos municípios que vêm recebendo importantes plantas industriais e logísticas e que possuem alta densidade de condições gerais de produção, ou seja, um processo de periferização da população, não mais no âmbito dos limites da metrópole, mas em sua área de expansão. 0 Mapa 2 evidencia tal movimento.

No Mapa 2, fica evidenciada a relevância local de Aracruz, Linhares e São Mateus, pela atração dos fluxos migratórios de municípios vizinhos. Mais importante, entretanto, são os fluxos originados nos municípios da RMGV, configurando claramente essa porção do litoral norte do Espírito Santo como área de expansão metropolitana. Isso confirma que, para além do aumento da imigração, há fluxos diretamente da RMGV, guardando semelhanças com movimentos de expansão intrametropolitana observados até então. Essa novidade está relacionada ao novo conteúdo espacial resultante do processo de metropolização do espaço no Espírito Santo. 
Mapa 2 - Origem dos imigrantes de Aracruz, Linhares e São Mateus.

Espírito Santo, 2005-2010
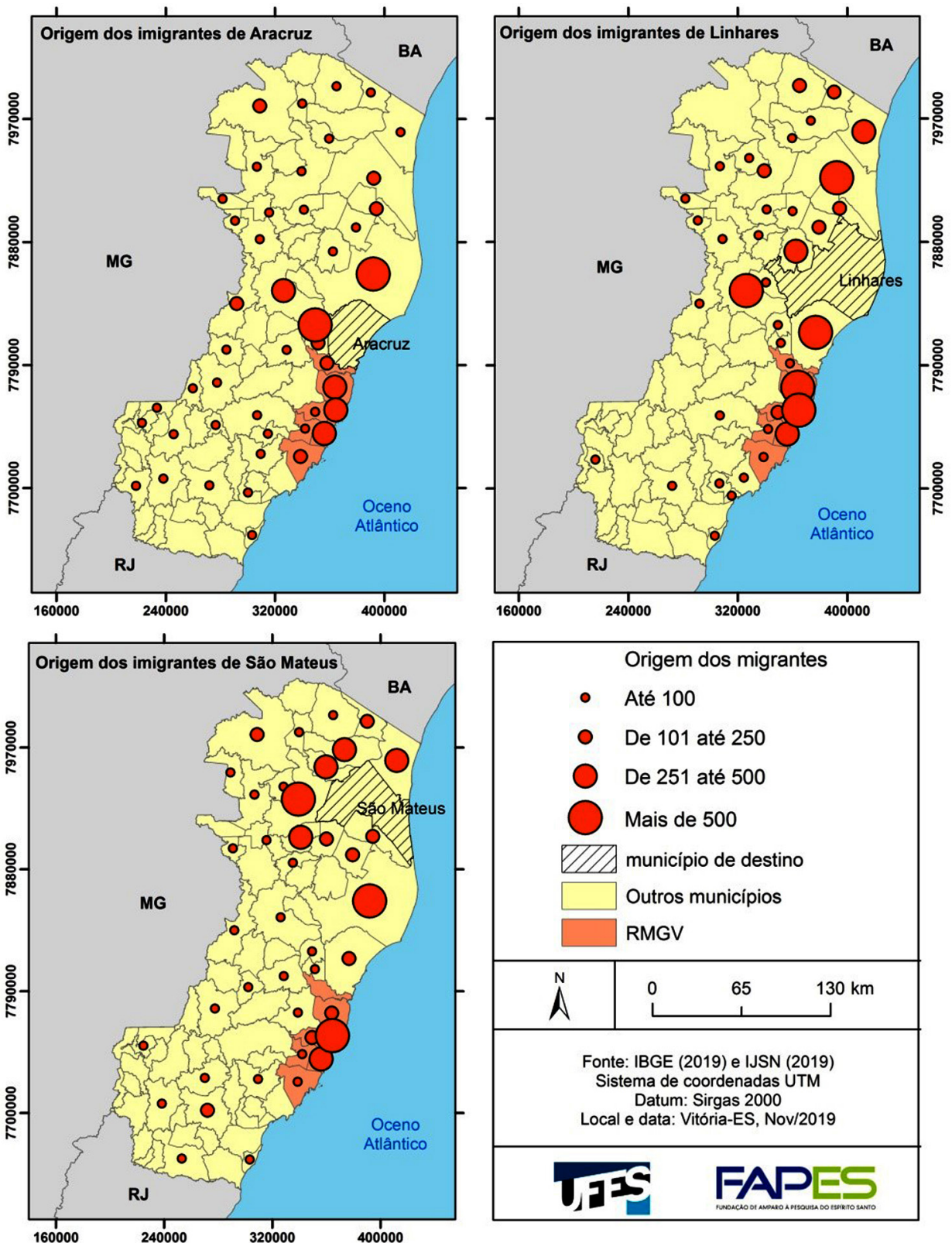

Fonte: IBGE. Censo Demográfico de 2010. 
O crescimento populacional, associado aos fluxos migratórios, em especial de pessoas que deixaram a RMGV, fez com que dinâmicas antes restritas à RMGV se expandissem para Aracruz, Linhares e São Mateus. Como exemplo, a forma de produção do espaço urbano associada à produção imobiliária de mercado, via condomínios (verticais e horizontais) e loteamentos fechados, passou a desenvolver suas estratégias de obtenção de lucros e rendas fundiárias e imobiliárias nesses municípios. Construtoras como a Lorenge ${ }^{4}$ e a Cobra Engenharia ${ }^{5}$ lançaram empreendimentos residenciais e comerciais em Linhares e Aracruz. Destaca-se, também, a construção de um loteamento fechado em Linhares, o Terras Alphaville Linhares, construído pela Alphaville Urbanismo, que pertence ao fundo de investimento brasileiro Pátria, ligado ao fundo de investimentos americano The Blackstone Group, que atua em escala global. Soma-se a isso o desenvolvimento de várias construtoras de capital local que também passaram a produzir empreendimentos de tipologias que antes se restringiam às metrópoles. Um exemplo desse caso é a empresa MV participações de Linhares, que iniciou suas atividades no setor agrícola e posteriormente criou a empresa Solidus, para o segmento da construção civil. ${ }^{6}$

Além disso, empresas loteadoras que atuavam em períodos anteriores na RMGV estão laçando loteamentos em Aracruz, Linhares e São Mateus. É o caso da loteadora Companhia Brasileira de Loteamentos (CBL) e da loteadora Grupo Cap Empreendimentos Imobiliários, que atuam em diversas cidades médias e regiões metropolitanas do Sudeste, Sul, Centro-Oeste e Nordeste. Por fim, condomínios logísticos e industriais (dois empreendimentos dessa tipologia em Linhares - Ecopark e o VTO Linhares) e os shoppings (Shopping Oriundi em Aracruz e Shopping PátioMix em Linhares) também eram produtos exclusivos da RMGV, e agora são observados nessa área de expansão metropolitana.

Outro elemento que permite afirmar a expansão metropolitana para os municípios do litoral norte do Espírito Santo é a mobilidade pendular para trabalho: analisando o Gráfico 1 , nota-se uma volumosa mobilidade pendular entre os municípios da RMGV e Aracruz, Linhares e São Mateus. Das 2,6 mil pessoas que se deslocavam para Aracruz entre os municípios analisados em 2010, 79,9\% saíam da RMGV, sendo 30,0\% (808 pessoas) de Serra. Das 1,6 mil pessoas que se deslocavam para Linhares, 55,2\% saíam da RMGV. Quanto a São Mateus, destaca-se que das 715 pessoas, 69,2\% saíam da RMGV.

A mobilidade pendular para trabalho particulariza-se pela abrangência espacial, afinal, tem-se, no Espírito Santo, o desenvolvimento de volumosos fluxos de mobilidade pendular em longas distâncias, que partem da metrópole para municípios não metropolitanos, intimamente associados à indústria do petróleo presente em Linhares e São Mateus (Zanotelli et al., 2019).

Em resumo, a desconcentração concentrada das unidades industriais e logísticas, a densidade das condições gerais de produção, a migração da região metropolitana, a expansão da produção imobiliária e a mobilidade pendular demonstram intensas interações entre a RMGV e os municípios de Aracruz, Linhares e São Mateus. Essas interações, de acordo com Lencioni (2003 e 2017), Moura (2009), Smith (1998) e Rua (2015a e 2015b), indicam e 
Gráfico 1 - Pessoas que realizavam mobilidade pendular para trabalhar

em São Mateus, Linhares e Aracruz segundo município de residência em 2010

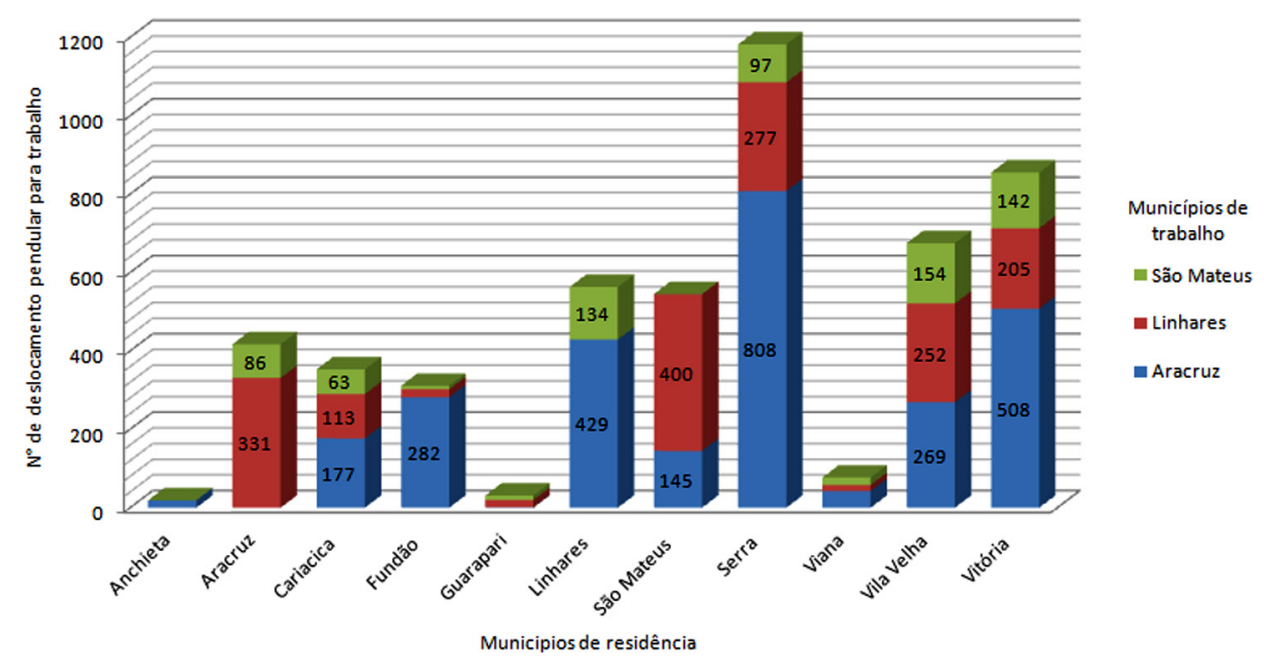

Fonte: Censo Demográfico do IBGE de 2010.

apresentam-se como aspectos capazes de metamorfosear o conteúdo do espaço, conferindo a ele aspectos metropolitanos por meio do processo de metropolização. Tais elementos, portanto, permitem afirmar que há transformação no processo urbano do Espírito Santo, mais especificamente está ocorrendo a metropolização do espaço no litoral norte, num processo de expansão a partir da RMGV.

\section{Considerações finais}

A análise da metropolização no Espírito Santo destaca dois elementos fundamentais: de um lado, que o processo está se expandindo para além dos limites institucionalizados da RMGV, colocando esse recorte como limitado para grande parte das análises que usam a metrópole enquanto recorte espacial; de outro, que os elementos usados neste artigo para análise e delimitação do processo de metropolização apresentam grande potencial explicativo, merecendo ser mais bem analisados em seu conjunto.

No caso específico do Espírito Santo, a análise confirma a proposição de uma RMGV expandida, diferente da proposta por Zanotelli et al. (2014), que aponta uma expansão do processo urbano de caráter qualitativo da RMGV para os municípios de Aracruz e Anchieta. Notou-se que a expansão do processo urbano se intensifica na região litorânea, em especial em sua porção norte, para os municípios de Aracruz, Linhares e São Mateus. Esses municípios estão passando por transformações quantitativas e qualitativas que se encontram, dentre outras coisas, associadas à metropolização. 
O trabalho, nesse sentido, além de analisar o processo no Espírito Santo, buscou apresentar uma proposta teórico-metodológica para a delimitação do processo de metropolização, fruto de pesquisas e reflexões em andamento. Enquanto proposta, portanto, há que se avançar e refletir, mas o caminho, sem dúvidas, passa pelo uso conjunto de indicadores, processos e fenômenos, além da observação em campo, que juntos, considerando a origem de suas ocorrências, podem contribuir para uma melhor compreensão das transformações em andamento.

Os quatro elementos que compõem a análise (a distribuição das plantas industriais e logísticas; a distribuição espacial das condições gerais de produção; a mobilidade pendular para trabalho e a migração) são tradicionalmente considerados na literatura dos estudos urbanos e regionais (Smith, 1988; Acher, 1998; Lencioni, 2003; 2007;
2013; Moura, 2009; Cunha, 2018), mas a articulação deles em conjunto ainda foi pouco explorada, visto que representam temas de recortes disciplinares distintos, cobrindo desde a geografia econômica e a economia espacial, até os estudos de população, no âmbito da geografia da população e da demografia, destacando a necessidade de trabalhos multidisciplinares para enxergar a complexidade dos processos urbanos, econômicos e sociais recentes.

Vale ressaltar que a proposição apresenta grande possibilidade para se pensar outras realidades da metropolização, em outros recortes territoriais e diferentes escalas, isso, pois, o objetivo não é o de distinguir o urbano e o rural ou definir uma morfologia urbana, mas o de identificar onde a metropolização do espaço se desenvolve de maneira mais intensa, conformando uma produção do espaço desigual e combinada.

\section{[I] http://orcid.org/0000-0002-8726-0424}

Universidade Federal do Espírito Santo, Departamento de Geografia, Programa de Pós-Graduação em Geografia. Vitória, ES/Brasil.

ednelson.dota@ufes.br

\section{[II] https://orcid.org/0000-0001-5232-8815}

Universidade Federal do Espírito Santo, Departamento de Geografia, Programa de Pós-Graduação em Geografia. Vitória, ES/Brasil.

francismar.cunha@gmail.com 


\section{Notas}

(1) Lencioni, (2013, p. 72) aponta que existem cidades de porte médio nas quais se verifica o processo de metropolização por estarem diretamente relacionadas à economia global; assim apresentam algumas condições gerais de produção e determinados serviços que, anteriormente, só eram encontrados nas metrópoles modernas.

(2) As análises de Smith (1988) não se limitam apenas à mobilidade pendular fisicamente. Ele levanta o debate referente aos custos do deslocamento da força de trabalho, entretanto não aprofunda em metodologias de análises sobre o assunto.

(3) A Região Metropolitana da Grande Vitória, instituída por lei estadual, é composta por sete municípios: Cariacica, Fundão, Guarapari, Serra, Viana, Vila Velha e a capital Vitória. Vale ressaltar que a área conurbada é formada apenas por Cariacica, Vila Velha, Serra e Vitória. A região tem uma área de $2.311 \mathrm{~km}^{2}$, apresenta uma densidade demográfica de $730 \mathrm{hab} / \mathrm{km}^{2} \mathrm{e}$ abriga aproximadamente $50 \%$ da população do Espírito Santo.

(4) Os empreendimentos lançados pela Lorenge em Aracruz e Linhares podem ser visualizados no link: https://www.lorenge.com.br/imoveis/?buscar=true\&localidade $=14,3$

(5) Os empreendimentos lançados pela Cobra Engenharia em Aracruz e Linhares podem ser visualizados no link: http://cobraengenharia.com.br/empreendimentos/

(6) Para maiores informações sobre o grupo MV participações, ver: http://www. residencialmoradadosipes.com/

\section{Referências}

ASCHER, F. (1998). Metapolis: acerca do futuro da cidade. Oeiras, Celta.

BRANDÃO, C. (2007). Território e desenvolvimento. As múltiplas escalas entre o local e o global. São Paulo, Editora da Unicamp.

CASTELLS, M. (1993). A era da informação: economia, sociedade e cultura. São Paulo, Paz e Terra. (1999). A questão urbana. Rio de Janeiro, Paz e Terra.

CUNHA, J. M. P. (1994). Mobilidade populacional e expansão urbana: o caso da Região Metropolitana de São Paulo. Tese de Doutorado. Campinas, Universidade Estadual de Campinas.

(2016). Aglomerações urbanas e mobilidade populacional: o caso da Região Metropolitana de Campinas. Revista Brasileira de Estudos de População. São Paulo, v. 33, n. 1, pp. 99-127. Disponível em: <http://www.scielo.br/scielo.php?script=sci_arttext\&pid=S0102-30982016000100099\&lng $=e n \& n r m=i s o>$. Acesso em: 19 jul 2019.

(2018). (org.) Dinâmica demográfica e socioespacial no Brasil Metropolitano: convergências e especificidades regionais. São Carlos, Editora Ufscar. 
CUNHA, J. M. P.; STOCO, S.; DOTA, E. M.; NEGREIROS, R.; MIRANDA, Z. A. I. (2013). A mobilidade pendular na Macrometrópole Paulista: diferenciação e complementaridade socioespacial. Cadernos Metrópole. São Paulo, v. 15, n. 30. Disponível em: <https://revistas.pucsp.br/metropole/article/ view/17490>. Acesso em: 15 abr 2019.

DOTA, E. M. (2015). Mobilidade residencial intrametropolitana na RM de Campinas: uma abordagem a partir da distribuição espacial dos migrantes. Tese de Doutorado. Campinas, Universidade Estadual de Campinas. Disponível em: http://repositorio.unicamp.br/bitstream/REPOSIP/281171/1/ Dota_EdnelsonMariano_D.pdf. Acesso em: 18 jul 2019.

(2019). Migração e o setor de petróleo e gás no Espírito Santo. In: XVI SIMPÓSIO NACIONAL DE GEOGRAFIA URBANA. Anais... Vitória.

DOTA, E. M.; FERREIRA, F. C. (2019). “Mobilidade espacial da população e planejamento: considerações sobre a Região Metropolitana da Grande Vitória (RMGV)." In: LYRA, A. P. R.; FERREIRA, G. L.; FERREIRA, G. A. C.; LIRA, P. S. (orgs.). Cidade e Metrópole: coleção arquitetura e cidade. Rio de Janeiro, Letra Capital/Observatório das Metrópoles.

DOTA, E. M.; COELHO, A. L. N.; CAMARGO, D. M. (2017). Atlas da migração no Espírito Santo. Vitória, UFES, Proex. Disponível em: http://www.geo.ufes.br/sites/geografia.ufes.br/files/field/anexo/ atlas3.pdf. Acesso em: 15 nov 2019.

EDP - Energias do Brasil S.A. (2017). Shapefille das linhas de transmissão de energia do Espírito Santo.

FERREIRA, F. C. (2014). A produção imobiliária e a renda da terra: estudos de alguns casos na Região Metropolitana da Grande Vitória (RMGV). Monografia. Vitória, Universidade Federal do Espírito Santo.

GOTTMAN, J. (1970). “A urbanização e a paisagem americana: o conceito de megalópole”. In: COHEN, S. B. (org.). Geografia humana nos Estados Unidos. Rio de Janeiro, Fórum (Estante de Ciências Sociais).

IJSN - INSTITUTO JONES DOS SANTOS NEVES. Espírito Santo em mapas. Disponível em: http://www. ijsn.es.gov.br/mapas/. Acesso em: 16 jul 2019.

LENCIONI, S. (2003). A emergência de um novo fato urbano de caráter metropolitano em São Paulo. A particularidade de seu conteúdo socioespacial, seus limites regionais e sua interpretação teórica. X ENCONTRO NACIONAL DA ANPUR. Anais... Belo Horizonte, MG.

(2007). Condições gerais de produção: um conceito a ser recuperado para a compreensão das desigualdades de desenvolvimento regional. Scripta Nova, v. XI, n. 245 (07).

(2013). "Metropolização do espaço: processos e dinâmicas”. In: FERREIRA. A; RUA, J.; MARAFON, G. J.; SILVA, A. C. P. (orgs.). Metropolização do espaço: gestão territorial e relações urbano-rurais. Rio de Janeiro, Consequência.

(2015). "Metropolização do espaço: processos e dinâmicas". In: FERREIRA, A.; RUA, J.; MATTOS, R. C. Desafios da metropolização do espaço. Rio de Janeiro, Consequência.

(2017). Metrópole, metropolização e regionalização. Rio de Janeiro, Consequência.

LEROY, S. (2000). Sémantiques de la métropolisation. L'Espace géographique. Montpellier, Éditions Belin, n. 1, pp. 78-86. 
LOBO, C.; CUNHA, J. M. P. da (2019). Migration and commuting in the areas of influence of the brazilian metropolises. Mercator. Fortaleza, v. 18. Disponível em: http://www.mercator.ufc.br/mercator/ article/view/e18017. Acesso em: 4 fev 2020.

MATOS, R. (2005). Periferias de grandes cidades e movimentos populacionais. Cadernos Metrópole. São Paulo, n. 13, pp. 71-105.

MONCLÚS, F. J. (1998). "Suburbanización y nuevas periferias. Perspectivas geográfico-urbanísticas". In: MONCLÚS, F. J. (ed.). La ciudad dispersa. Barcelona, Centro de Cultura Contemporánea de Barcelona.

MOURA, R. (2009). Arranjos urbano-regionais no Brasil: uma análise com foco em Curitiba. Tese de doutorado. Curitiba, Universidade Federal do Paraná.

OLIVEIRA, F. (1982). O Estado e o Urbano no Brasil. Revista Espaço e Debates, v. 6, p. 37.

PETROBRAS (2019). Programa de Comunicação Social regional da bacia. Disponível em: https:// www.comunicabaciadesantos.com.br/programa-ambiental/programa-de-comunicacao-socialregional-da-bacia-de-santos-pcsr-bs.html. Acesso em: 20 dez 2019.

RUA, J. (2015a). "O preço da terra e os megaprojetos como marcantes urbanidades no rural na fase atual de organização do espaço geográfico". In: FERREIRA, A.; RUA, J.; MATTOS, R. C. (orgs.). Desafios da metropolização do espaço. Rio de Janeiro, Consequência.

(2015b). "O urbano no rural fluminense e o preço da terra". In: FERREIRA, A.; RUA, J.; MATTOS, R. C. (orgs.). Desafios da metropolização do espaço. Rio de Janeiro, Consequência.

SCOTT, A. J.; AGNEW, J.; SOJA, E. W.; STORPER, M. (2001). Cidades-regiões globais. Espaço e Debates. São Paulo, n. 41, pp. 11-25.

SILVA, K. A. A.; CUNHA, J. M. P.; ORTEGA, G. M. (2017). Um olhar demográfico sobre a constituição da macrometrópole paulista: fluxos populacionais, integração e complementaridade. Cadernos Metrópole. São Paulo, v. 19, n. 40, pp. 721-748.

SILVA, K. A. A. (2018). Novas formas urbanas e olhar através da demografia: a estruturação da cidade-região paulista. Tese de Doutorado. Campinas, Universidade Estadual de Campinas.

SINGER, P. (1976). Economia política e urbanização. Cebrap, Brasiliense.

SMITH, N. (1988). Desenvolvimento desigual: natureza, capital e a produção de espaço. Rio de Janeiro, Bertrand Brasil.

SOJA, E. W. (2002). Postmetropolis: critical studies of cities and regions. Oxford, Blackwell Publishing.

ZANOTELLI, C. L.; FERREIRA, F. C.; ANTONIO, L; e BERGAMASHI, R. B. (2014). A renda da terra na Região Metropolitana da Grande Vitória- ES, Brasil. Confins. Paris, v. 21, pp. 1-25.

ZANOTELLI, C. L.; DOTA, E. M.; FERREIRA, F. C.; RODRIGUES, R. M. (2019). Bacia urbano-regional do petróleo: a zona costeira do Espírito Santo associada ao estado do Rio de Janeiro. Confins. Paris, v. 1 , pp. $1-25$

Texto recebido em $12 / \mathrm{fev} / 2020$

Texto aprovado em 24/abr/2020 